Max-Planck-Institut für demografische Forschung

Max Planck Institute for Demographic Research

Konrad-Zuse-Strasse 1 · D-18057 Rostock · GERMANY

Tel +49 (0) 3812081 - 0; Fax +49 (0) 3812081 - 202;

http://www.demogr.mpg.de

MPIDR WORKING PAPER WP 2015-005

OCTOBER 2015

\title{
Why does paternal death accelerate \\ the transition to first marriage in the \\ C18-C19 Krummhörn population?
}

Eckart Voland

Kai P. Willführ (willfuehr@demogr.mpg.de)

This working paper has been approved for release by: Mikko Myrskylä (sekmyrskyla@demogr.mpg.de), Head of the Laboratory of Population Health and Head of the Laboratory of Fertility and Well-Being.

(C) Copyright is held by the authors.

Working papers of the Max Planck Institute for Demographic Research receive only limited review. Views or opinions expressed in working papers are attributable to the authors and do not necessarily reflect those of the Institute. 
Why does paternal death accelerate the transition to first marriage in the C18-C19 Krummhörn population?

\author{
Eckart Voland ${ }^{1}$ \& Kai P. Willführ ${ }^{2}$ \\ ${ }^{1}$ Institute for Philosophy, Justus-Liebig University Giessen, Germany \\ ${ }^{2}$ Max-Planck-Institute for Demographic Research Rostock, Germany
}

\begin{abstract}
In the population of the Krummhörn (Ostfriesland, Germany) in the $18^{\text {th }}$ and $19^{\text {th }}$ centuries, paternal death led to an accelerated marriage of his children on average. Three evolutionary explanations are offered for this "paternal absence" effect in the literature, namely (i) the assumption of an adaptive "psychosocial acceleration" of the children with prepubertal experience of uncertainty within the framework of evolutionary life history theory, (ii) an adaptive adjustment of life and reproduction decisions within the theoretical framework of behavioral ecology as a reaction to the personal cost-benefit balances changed by the father's death, and (iii) in view of the genetic parent-offspring conflict, an increase in the reproductive autonomy of offspring after the loss of the dominant father figure. Our models, which are based on the analyses of the vital-statistics data derived primarily from church registers and compiled into a family reconstitution study, attribute the greatest explanatory power to the behavioral ecology approach (ii) for the circumstances in the Krummhörn.
\end{abstract}

\title{
1. Introduction
}

Frequently, paternal absence accelerates the transition of juveniles into their reproductive life phase (see Shenk et al. 2013 and Sheppard et al. 2014 for recent overviews). With regard to this phenomenon, it is assumed that it could be the manifestation of an adaptive regulation, although it is not always clear which evolutionary functional logic could be responsible for this. Three theory offerings that take a position on this issue are discussed, but their attempts at explanation point into three different directions.

The proposal made by Draper and Harpending (1982) has had a lasting influence on later research. Accordingly, the absence of the father in the life of a growing up child is interpreted as an indicator of socially and ecologically uncertain living conditions. Belsky et al. (1991), Ellis (2004), Chisholm (1993) and others have further differentiated this approach 
and sharpened it into the hypothesis that children accelerate their reproductive pathway as an adaptive response to life stress and unpredictability, and by this means they counteract the external life and survival risks in terms of reproductive strategy (see Brumbach et al. 2009 for a full account of this argument and Webster et al. 2014 for a meta-analysis of the strengths of this effect.) Recently, Rickard et al. (2014) have proposed that the "external prediction model" be augmented by an "internal prediction model". The authors argue that early adversity may detrimentally affect reproductive value by increasing later morbidity and mortality. Whatever the case may be, both prediction models are based on the assumption of reproductive strategy remote effects on prepubertal life experiences, which are implemented ontogenetically through phenotypic plasticity. Due to its theoretical origin, this line of argument is to be described in the following as a Life History Theory (LHT) explanation attempt.

However, it could also be that a possible acceleration of one's life history after the death of one's father is very directly connected to the loss of solid social transactions between the father and his offspring, i.e., in the broadest sense to the loss of paternal investment (Sheppard et at. 2014, Scelza 2010) and to the resulting change in family dynamics as a whole.

Intrafamilial resource streams change with the death of a person from the family network, and this leads to a re-evaluation of the cost-benefit balances of various behavioral options. The decision regarding whether to remain with the family as a helper or to independently reproduce could be affected by this and possibly be revised in favor (or even against) one's own reproduction. In accordance with the view of the human family as a manifestation of a cooperative breeding system, effects of this kind should be influenced by both the family's resource background and also by the size and composition of the family, because both are associated with impacts on the individual cost-benefit balances of various behavioral options. In the following, we shall describe this line of argument as a Behavioral Ecology (BE) explanation attempt. Basically, the assumption is that reproductive strategy decisions will be made conditionally in the direct time horizon, i.e., opportunistically, without long-term physiological regulation being necessary.

However, fathers not only appear as investors of caloric and social resources, which could favor the transition of their children into marriage, but also as the manager of their own interests in the reproductive decisions of their offspring, which could make the transition of their children into marriage more difficult (Apostolou 2014). With the decease of the father, the parent-offspring conflict acquires a new face. It cannot be ruled out that children gain in reproductive autonomy after the loss of their father and therefore could enter into a marriage 
because they have less need to align their own interests with those of their father. The essential element of this assumption is that the intrafamilial "helper-conflict" (Voland 2014) could be noticeably less pronounced with the absence of the father. This line of argumentation is to be referred to as the parent-offspring conflict (POC) explanation attempt.

The three aforementioned explanatory models are partly based on different assumptions and requirements. The LHT explanation attempt demands the experience of the loss of one's father in a child's early years of life (Belsky et al. 1991), and it does not expect any significant difference between the social groups of a population. Within the framework of this theory, paternal loss should have a similar impact in every social stratum, because the "psychosocial acceleration" (Ellis 2004) is conceived of as a species-specific adaptation, which develops its impact across cultures and social groups.

On the other hand, the BE explanation attempt focuses on the loss of a father during and in particular after adolescence, i.e., during the life phase when marriage options are increasingly being contemplated anyway. Furthermore, it is sensitive to the social situation of the families, especially the resource situation. Particularly in the large-scale farmer families of the historical agricultural society in the Krummhörn a marriage befitting one's social status was closely tied to the possession of a farm. If a position became vacant due to the father's death, this had not only consequences for the socio-economic status of his heirs and successors within the village community, but also made the transition into marriage easier. Behavioral ecological influences are also to be expected from the sibling scenario, because this is a crucial component for economic performance and thus for a family's pooled energy budget (Kramer et al. 2009, Reiches et al. 2009). As facultative cooperative breeders, young adults see themselves faced with the trade-off of remaining in their natal family as a helper or commencing with their own reproduction. The death of one's father was likely to have a lasting impact on the helper or breeder decision and hence on the age at marriage as well.

Finally, the POC explanation attempt is agnostic with regard to the time of paternal loss. Social-group differences are to be expected, insofar as that due to the interaction of economic and generative interests, paternal dominance and therefore expectations with regard to the lifestyle of the children as well are likely to have been more strongly pronounced in propertyowning families on average, than in non-property-owning families. With the father's death, restrictions on personal autonomy caused by the family situation are reduced. Ultimately, this includes issues of mate selection and the time of the marriage. On the other hand, no significant influence is to be expected from the sibling scenario, because as a rule, no restrictive effects on reproductive autonomy come from siblings. Although it is conceivable 
that sibling conflicts might break out with the loss of the father which would not remain without effect on the reproductive decisions of the persons involved, yet these decisions are not forced by the pressure of intrafamilial dominance, but in accordance with one's personal costs-benefits balances.

The following matrix with predictions concerning the timing, resource and sibship influences on the paternal absence effect is derived from the three lines of argumentation (table 1), the empiric examination of which should allow a differentiating assessment of the three functional correlations between paternal loss and accelerated transition into the reproductive life phase.

Table 1: Expected correlations between paternal death and the accelerated transition into the reproductive life phase for three evolutionary theories

\begin{tabular}{|c|c|c|c|}
\hline & $\begin{array}{l}\text { Time of the loss of the } \\
\text { father }\end{array}$ & $\begin{array}{l}\text { Family resource } \\
\text { situation }\end{array}$ & $\begin{array}{c}\text { Sibship size and } \\
\text { age/sex } \\
\text { composition }\end{array}$ \\
\hline $\begin{array}{l}\text { LHT explanation } \\
\text { attempt }\end{array}$ & $\begin{array}{c}\checkmark \text { (only prepubertal loss } \\
\text { is effective) }\end{array}$ & - & - \\
\hline $\begin{array}{l}\text { BE explanation } \\
\text { attempt }\end{array}$ & $\begin{array}{c}\checkmark \text { (in particular } \\
\text { postpubertal loss is } \\
\text { effective) }\end{array}$ & $\checkmark$ & $\checkmark$ \\
\hline $\begin{array}{l}\text { POC explanation } \\
\text { attempt }\end{array}$ & $\mathrm{O}$ & $\checkmark$ & - \\
\hline
\end{tabular}

With this study, we are focusing on the consequences of paternal death for the transition to starting a family in the agricultural population of the Krummhörn (Ostfriesland, Germany) in the $18^{\text {th }}$ and the $19^{\text {th }}$ centuries. The church register entries as well as information from the local tax rolls have been compiled through a family reconstitution study and permit the analysis of complex family networks. In this population, paternal absence practically always means that the father has died. Although divorces were not ruled out, they were tied to exceptional special conditions and thus practically never happened. Occasionally, the "disappearance" of a husband was reported, but this possibility too is quantitatively absolutely marginal. Paternal absence due to work mobility is a bit more difficult to assess. Although the population of the Krummhörn is deemed to have produced a demographic surplus, which led to the emigration of single persons or whole families (such as in connection with long- 
distance migration to America), yet due to the high demand for labor in the profitable agricultural economy of this fertile marsh region, local fathers found work near where they lived with a high degree of probability, so that a permanent absence of fathers for reasons of seasonal work migration was not a significant family sociology factor. Accordingly, we assume that if the father did not die, he was present in the families and think that we are very close to the living reality of this population. To summarize the hypothesis, are there any statistical correlations between paternal death and the timing of the onset of the first marriage of the offspring and which factors, if any, moderate these correlations?

\section{Methods}

\subsection{The population of the Krummhörn region, in the $18^{\text {th }}$ and $19^{\text {th }}$ centuries}

The historical Krummhörn region (Ostfriesland, a coastal region in north-west Germany) consists of 33 parishes, for which all of the church register entries and information from the tax rolls are available in the format of a family reconstitution (Voland 2000). The historical population of the Krummhörn region was an agricultural and early capitalistic society, where a few wealthy families owned the majority of the farmland (for details, see Willführ and Störmer, in press). The overwhelming majority of the population worked either as craftsmen (with no or only marginal land ownership) or as landless agricultural workers on the farms of the resource-holding wealth elite. A small fraction of the population owned farms big enough to provide goods at a subsistence level. There have been no urban settlements in the study area, even if the city of Emden directly bordered the Krummhörn and surely exercised a demographic pulling effect in its very immediate vicinity. The impact of this is likely to have been more limited, because the marsh soil is very fertile and good for both crops and livestock. Within the study period, there were no famines or wars. Settlement of the area had been completed by the late medieval era (Ohling 1963), und due to the natural limitation of this region by the North Sea and formerly impassable moor landscapes, there was no significant population growth during the study period. Therefore, the Krummhörn region is in contrast to the general development of the population increase, especially during the $19^{\text {th }}$ century in Germany, including other parts of Ostfriesland.

\subsection{Data selection and study period}


We included children who were born within marriages contracted after 1720 when church registers can be regarded as being acceptably accurate $(\mathrm{N}=76,741)$. Children who were not the offspring of a first marriage of both spouses are excluded (32,815 cases deleted) as the levels of parental investment often vary between children from different marriages due to the altering of kinship relations (Willführ and Gagnon 2013). A further selection criterion was that the reproductive career of the natal family had to be completely known. This is fulfilled, if dates for the marital beginning and end (i.e., the death of one spouse and survival of the other) are exactly known (17,763 cases deleted). In 1874, churches were no longer responsible for maintaining the birth, death, and marriage registers, since these tasks were assigned to the civil administration. Due to this, every date past 1874 needs to be censored in order to avoid selection biases.

The study by Willführ and Störmer (in press) has shown that the age at first marriage differed substantially between the social strata. Therefore, it is necessary to control for the family's social rank in the models. However, since information from the tax rolls about land ownership and social status is only comprehensively available for marriages contracted between 1720 and 1810, our models are restricted to children born in marriages contracted within this time period. The aforementioned data selection criteria result in a sample containing 17,368 individuals. After exclusion of the cases with missing data on an individual's sex (118 cases deleted), the exact date of birth (123 cases deleted), the exact date of marriage (446 cases deleted) and destination (394 cases deleted) and further on the exact death dates of the parents (143 cases deleted), our final sample included 8,296 boys and 7,855 girls from 3,467 families. Some 2,531 boys and 2,306 girls of these individuals in the sample died before the age of 15. Moreover, 1,883 boys and 1,637 girls emigrated out of the study area. Emigration is assumed if despite the completeness of the sources, neither a death entry nor a marriage entry exists. As the emigration of children independent of their parents can be deemed improbable, we assume that the children concerned lived in their natal families at least until their $15^{\text {th }}$ birthday. After that, they are removed from observation. For the remaining 3,882 boys and 3,912 girls, their destination after the age of 15 is known: 2,908 boys and 3,237 girls were married, whereas 974 boys and 675 girls died as single adults.

\subsection{Analytical methods}

We modeled the life courses of the boys and girls separately, commencing from birth until their first marriage (or until they were censored due to death or emigration, respectively) by using the Cox proportional hazard model (Cox 1972). Events experienced by the 
individuals, such as the births and deaths of siblings or paternal and maternal loss, are coded as time-varying covariates. Thus, the models include information on the number of living older and younger siblings and the vital status of their parents at every age for each individual.

Four different models are estimated in order to investigate timing effects in response to paternal loss. In all four models, the death of the father is coded as the dummy variable that differs with regard to child's age at the paternal loss. Model A includes the information on paternal death at every age of a child, while Model B only considers paternal loss before the age of five and equates paternal loss after the age of five with no paternal loss. Similarly, Model C only considers paternal loss between the ages of five and 15, and Model D only considers paternal death after the age of 15 . All models have been checked for a violation of the proportional hazard assumption and if violated, have been corrected by including the interaction of the respective covariate with age or time. In addition to the time varying covariates, such as the number of siblings, paternal death and maternal death, we included information on birth order, and maternal and paternal age at the child's birth.

In addition, all models (A, B, C, and D) are compiled in different versions with respect to the inclusion of confounding covariates. Model Version I is a minimal model and consists of the respective dummy variable coding for paternal loss (A, B, C, and D) and includes child's birth order and birth cohort as controls. Besides the child's birth order and the birth cohort, Model Version II also includes the social rank of the parents, paternal and maternal age at the child's birth and further time-varying covariates on the number of older and younger sisters and brothers, respectively, as well as the mother's life status. To investigate whether paternal loss affects the age of their children at marriage differently across social strata, we used Model Version III to estimate the interaction between social strata and paternal loss effects. Additionally, we estimate a series of family fixed-effects models based on sibling comparison (Model IV). Through sibling comparison, all observed and unobserved environmental and biological factors shared by the siblings are controlled for in the model (Allison 2009). For example, characteristics such as parental socioeconomic status, cognitive ability, or parental personality are, to the extent they do not vary between siblings, controlled. Time-varying and non-shared factors (such as birth order or parental age) are not automatically captured by the model. Consequently, we included controls for the observed non-shared factors of birth order, maternal age and paternal age at the child's birth.

\section{Results}


Descriptive statistics are given in Table 2, the results of regression analyses for the girls' age at first marriage are given in Table 3 and those for the boys' age at first marriage are given in Table 4. For the sake of clarity, Models I (minimal model) and IV (fixed-effect model) are not listed.

Table 2: Descriptive statistics: Number of cases and mean ages at first marriage

\begin{tabular}{|c|c|c|c|c|c|c|}
\hline \multirow[b]{2}{*}{ TOTAL } & \multicolumn{3}{|c|}{ GIRLS } & \multicolumn{3}{|c|}{ BOYS } \\
\hline & $\begin{array}{l}\text { N Girls } \\
\text { born }\end{array}$ & $\begin{array}{l}\text { N Girls } \\
\text { married }\end{array}$ & $\begin{array}{l}\text { Mean age } \\
\text { at } 1^{\text {st }} \\
\text { marriage }\end{array}$ & $\begin{array}{l}\text { N Boys } \\
\text { born }\end{array}$ & $\begin{array}{l}\text { N Boys } \\
\text { married }\end{array}$ & $\begin{array}{l}\text { Mean age } \\
\text { at } 1^{\text {st }} \\
\text { marriage }\end{array}$ \\
\hline & 7853 & 3238 & $\begin{array}{l}26.340 \\
( \pm 5.367)\end{array}$ & 8291 & 2908 & $\begin{array}{l}28.911 \\
( \pm 5.759)\end{array}$ \\
\hline & $\begin{array}{c}\text { Not } \\
\text { married }\end{array}$ & Married & $\begin{array}{l}\text { Mean age } \\
\text { at } 1^{\text {st }} \\
\text { marriage }\end{array}$ & $\begin{array}{c}\text { Not } \\
\text { married }\end{array}$ & Married & $\begin{array}{l}\text { Mean age } \\
\text { at } 1^{\text {st }} \\
\text { marriage }\end{array}$ \\
\hline No paternal loss & 3,633 & 1,751 & $\begin{array}{l}25.208 \\
( \pm 4.227)\end{array}$ & 4,173 & 1,425 & $\begin{array}{l}27.657 \\
( \pm 4.761)\end{array}$ \\
\hline Paternal loss & 982 & 1,487 & $\begin{array}{l}27.672 \\
( \pm 6.198)\end{array}$ & 1210 & 1,483 & $\begin{array}{l}30.116 \\
( \pm 6.349) \\
\end{array}$ \\
\hline $\begin{array}{l}\text { No paternal loss before the } \\
\text { age of } 5\end{array}$ & 4,357 & 3,075 & & 5,119 & 2,745 & \\
\hline Paternal loss before the age of 5 & 258 & 163 & $\begin{array}{l}26.172 \\
( \pm 5.248)\end{array}$ & 264 & 163 & $\begin{array}{l}28.545 \\
( \pm 5.698) \\
\end{array}$ \\
\hline $\begin{array}{l}\text { No paternal loss between the age } \\
\text { of } 5 \text { and } 15\end{array}$ & 4,166 & 2,763 & & 4,794 & 2,470 & \\
\hline $\begin{array}{l}\text { Paternal loss between the age of } \\
5 \text { and } 15\end{array}$ & 449 & 475 & $\begin{array}{l}26.123 \\
( \pm 5.647)\end{array}$ & 589 & 438 & $\begin{array}{l}29.096 \\
( \pm 5.784)\end{array}$ \\
\hline No paternal loss after the age of 15 & 4,366 & 2,402 & & 5,048 & 2,036 & \\
\hline Paternal loss after the age of 15 & 249 & 836 & $\begin{array}{l}28.873 \\
( \pm 6.423)\end{array}$ & 335 & 872 & $\begin{array}{l}30.971 \\
( \pm 6.618)\end{array}$ \\
\hline
\end{tabular}




\subsection{Paternal death and transition to first marriage: strength of the effect}

The (minimal) Model AI which controls for the child's birth cohort and birth order indicates a significant decreasing impact of the father's death on the girls' age at first marriage (hazard ratio $=1.162 * *$ ) as well as on the boys' age at first marriage (hazard ratio $=$ $\left.1.113^{* *}\right)$. Similar results are indicated by Model IIA, which includes further potential confounding covariates such as the family's social rank, the number of older and younger brothers and sisters, paternal and maternal age at the child's birth and maternal loss (hazard ratios for girls $=1.165^{* *}$, Table 3 , and $1.096^{* *}$ for boys, Table 4). Also the consideration of the potential interaction between paternal absence and social rank (Model IIIA; hazard ratios for girls $=1.195^{+}$and $1.232^{+}$for boys) or the fixed-effect approach comparing siblings do not contradict this finding (Model IVA; hazard ratios for girls $=1.358^{*}$ and $1.551^{* *}$ for boys; data not shown). Thus, we find strong evidence that paternal loss was associated with earlier marriage for both boys and girls among the historical population of the Krummhörn region.

Table 3: Results of the Cox regression models estimating the girls' age at first marriage

\begin{tabular}{|c|c|c|c|c|c|c|c|c|}
\hline \multicolumn{9}{|l|}{ GIRLS } \\
\hline Model & A & $\mathrm{B}$ & $\mathrm{C}$ & $\mathrm{D}$ & A & $\mathrm{B}$ & $\mathrm{C}$ & $\mathrm{D}$ \\
\hline Version & II & II & II & II & III & III & III & III \\
\hline $\mathrm{N}$ girls & 7,851 & 7,851 & 7,851 & 7,851 & 7,851 & 7,851 & 7,851 & 7,851 \\
\hline $\mathrm{N}$ failures (marriages) & 3,238 & 3,238 & 3,238 & 3,238 & 3,238 & 3,238 & 3,238 & 3,238 \\
\hline Observation episodes & 38,594 & 38,594 & 38,594 & 38,594 & 38,594 & 38,594 & 38,594 & 38,594 \\
\hline Father dies & $1.165^{* *}$ & & & & $1.195+$ & & & \\
\hline Father dies before the age of 5 & & 0.994 & & & & 1.250 & & \\
\hline Father dies between the age of $5 \& 15$ & & & $1.102+$ & & & & 1.244 & \\
\hline Father dies after the age of 15 & & & & $1.143^{\star \star}$ & & & & 1.053 \\
\hline \multicolumn{9}{|l|}{ Social rank } \\
\hline (large-scale farmer is ref.) & 1 & 1 & 1 & 1 & 1 & 1 & 1 & 1 \\
\hline mid-scale farmers & 0.970 & 0.958 & 0.959 & 0.963 & 0.955 & 0.965 & 0.956 & 0.947 \\
\hline small-scale farmers & $0.833^{*}$ & $0.828^{*}$ & $0.831^{*}$ & $0.827^{*}$ & $0.838+$ & $0.848^{*}$ & $0.833^{*}$ & $0.808^{*}$ \\
\hline Landless & $0.723^{* *}$ & $0.723^{\star \star}$ & $0.721^{\star *}$ & $0.722^{\star *}$ & $0.737^{\star \star}$ & $0.727^{* \star}$ & $0.744^{\star *}$ & $0.706^{\star \star}$ \\
\hline Unknown & $0.704^{* *}$ & $0.719^{* *}$ & $0.714^{* *}$ & $0.719^{* *}$ & $0.721^{* *}$ & $0.736^{* *}$ & $0.729^{* *}$ & $0.699^{* *}$ \\
\hline \multicolumn{9}{|l|}{ Interaction social rank\#\#father's death } \\
\hline large-scale farmer (REF.) & & & & & 1 & 1 & 1 & 1 \\
\hline mid-scale farmers & & & & & 1.052 & 1.120 & 1.032 & 1.065 \\
\hline small-scale farmers & & & & & 0.987 & 0.555 & 1.043 & 1.093 \\
\hline Landless & & & & & 0.959 & 0.963 & 0.800 & 1.091 \\
\hline Unknown & & & & & 0.957 & 0.719 & 0.874 & 1.118 \\
\hline Mother dies & $1.155^{\star *}$ & $1.156^{\star *}$ & $1.157^{* *}$ & $1.151^{* *}$ & $1.157^{* \star}$ & $1.156^{* *}$ & $1.160^{* *}$ & $1.152^{\star *}$ \\
\hline \multicolumn{9}{|l|}{$\begin{array}{l}\text { Number of older brothers } \\
\text { (time varying) }\end{array}$} \\
\hline 0 & 1 & 1 & 1 & 1 & 1 & 1 & 1 & 1 \\
\hline
\end{tabular}




\begin{tabular}{|c|c|c|c|c|c|c|c|c|}
\hline 1 & $0.826^{\star *}$ & $0.823^{\star *}$ & $0.823^{\star *}$ & $0.824^{\star *}$ & $0.825^{* *}$ & $0.823^{\star *}$ & $0.822^{\star *}$ & $0.824^{\star \star}$ \\
\hline 2 & $0.801^{* \star}$ & $0.798^{\star \star}$ & $0.801^{\star *}$ & $0.802^{\star \star}$ & $0.801^{* \star}$ & $0.799^{* \star}$ & $0.798^{\star \star}$ & $0.801^{\star \star}$ \\
\hline $3+$ & $0.760^{\star \star}$ & $0.755^{\star \star}$ & $0.756^{\star \star}$ & $0.757^{\star \star}$ & $0.759^{\star \star}$ & $0.755^{\star \star}$ & $0.754^{\star \star}$ & $0.757^{* \star}$ \\
\hline \multicolumn{9}{|l|}{$\begin{array}{l}\text { Number of younger brothers } \\
\text { (time varying) }\end{array}$} \\
\hline 0 & 1 & 1 & 1 & 1 & 1 & 1 & 1 & 1 \\
\hline 1 & 0.944 & 0.939 & 0.935 & 0.942 & 0.943 & 0.938 & 0.937 & 0.943 \\
\hline 2 & $0.852^{\star \star}$ & $0.844^{\star \star}$ & $0.844^{\star \star}$ & $0.842^{\star \star}$ & $0.852^{\star \star}$ & $0.843^{\star \star}$ & $0.846^{\star \star}$ & $0.840^{\star \star}$ \\
\hline $3+$ & $0.858^{*}$ & $0.839^{*}$ & $0.845^{*}$ & $0.837^{\star}$ & $0.858^{*}$ & $0.838^{*}$ & $0.848^{*}$ & $0.837^{*}$ \\
\hline \multicolumn{9}{|l|}{$\begin{array}{l}\text { Number of older sisters } \\
\text { (time varying) }\end{array}$} \\
\hline 0 & 1 & 1 & 1 & 1 & 1 & 1 & 1 & 1 \\
\hline 1 & $0.815^{\star \star}$ & $0.816^{\star \star}$ & $0.817^{\star \star}$ & $0.815^{\star \star}$ & $0.816^{\star \star}$ & $0.814^{\star *}$ & $0.816^{* \star}$ & $0.814^{\star \star}$ \\
\hline 2 & $0.843^{*}$ & $0.842^{\star \star}$ & $0.841^{\star \star}$ & $0.846^{*}$ & $0.844^{*}$ & $0.841^{\star \star}$ & $0.841^{\star \star}$ & $0.845^{\star}$ \\
\hline $3+$ & $0.635^{\star \star}$ & $0.626^{* *}$ & $0.627^{\star \star}$ & $0.633^{* *}$ & $0.637^{\star *}$ & $0.633^{\star \star}$ & $0.625^{\star \star}$ & $0.631^{\star \star}$ \\
\hline \multicolumn{9}{|l|}{$\begin{array}{l}\text { Number of younger sisters } \\
\text { (time varying) }\end{array}$} \\
\hline 0 & 1 & 1 & 1 & 1 & 1 & 1 & 1 & 1 \\
\hline 1 & $0.869^{\star \star}$ & $0.861^{* *}$ & $0.862^{* *}$ & $0.858^{\star *}$ & $0.870^{\star *}$ & $0.861^{\star *}$ & $0.865^{\star \star}$ & $0.859^{\star \star}$ \\
\hline 2 & 0.948 & 0.934 & 0.939 & 0.928 & 0.948 & 0.933 & 0.940 & 0.928 \\
\hline $3+$ & 0.914 & $0.889+$ & 0.897 & $0.888+$ & 0.915 & $0.887+$ & 0.900 & $0.888+$ \\
\hline \multicolumn{9}{|l|}{ Paternal age } \\
\hline$<20$ & 0.708 & 0.708 & 0.710 & 0.706 & 0.722 & 0.706 & 0.719 & 0.699 \\
\hline 20-30 (REF.) & 1 & 1 & 1 & 1 & 1 & 1 & 1 & 1 \\
\hline $30-40$ & 0.978 & 0.990 & 0.987 & 0.982 & 0.979 & 0.989 & 0.987 & 0.982 \\
\hline $40-50$ & 0.948 & 0.967 & 0.962 & 0.961 & 0.951 & 0.976 & 0.964 & 0.962 \\
\hline $50-60$ & 0.853 & 0.888 & 0.872 & 0.878 & 0.851 & 0.895 & 0.880 & 0.882 \\
\hline \multicolumn{9}{|l|}{$>60$} \\
\hline Unknown & 0.962 & 0.981 & 0.975 & 0.974 & 0.962 & 0.978 & 0.975 & 0.973 \\
\hline \multicolumn{9}{|l|}{ Maternal age } \\
\hline$<20$ & 1.126 & 1.092 & 1.103 & 1.098 & 1.128 & 1.087 & 1.107 & 1.094 \\
\hline 20-30 (REF.) & 1 & 1 & 1 & 1 & 1 & 1 & 1 & 1 \\
\hline $30-35$ & 1.006 & 1.001 & 1.000 & 1.006 & 1.005 & 0.998 & 0.999 & 1.007 \\
\hline $35-45$ & $0.857^{\star}$ & $0.853^{\star}$ & $0.857^{\star}$ & $0.847^{\star}$ & $0.856^{*}$ & $0.847^{\star}$ & $0.856^{*}$ & $0.846^{\star}$ \\
\hline$>45$ & 0.949 & 0.944 & 0.951 & 0.923 & 0.950 & 0.935 & 0.951 & 0.919 \\
\hline Unknown & 0.980 & 0.974 & 0.978 & 0.972 & 0.979 & 0.974 & 0.977 & 0.972 \\
\hline $\begin{array}{l}\text { Child's birth cohort } \\
\text { (coded in decades) }\end{array}$ & 1.004 & 1.003 & 1.003 & 1.002 & 1.004 & 1.002 & 1.003 & 1.002 \\
\hline $\begin{array}{l}\text { Child's birth order } \\
\text { (1=firstborn) }\end{array}$ & $(0.008)$ & $(0.008)$ & $(0.008)$ & $(0.008)$ & $(0.008)$ & $(0.008)$ & $(0.008)$ & $(0.008)$ \\
\hline \multicolumn{9}{|l|}{ Standard errors in parentheses } \\
\hline${ }^{* \star} p<0.01,{ }^{*} p<0.05,+p<0.1$ & & & & & & & & \\
\hline
\end{tabular}

Table 4: Results of the Cox regression models estimating the boys' age at first marriage

\begin{tabular}{|l|l|l|l|l|l|l|l|l|}
\hline BOYS & & & & & & & & \\
\hline Model & A & B & C & D & A & B & C & D \\
\hline Version & II & II & II & II & III & III & III & III \\
\hline N boys & 8.291 & 8.291 & 8.291 & 8.291 & 8.291 & 8.291 & 8.291 & 8.291 \\
\hline N failures (marriages) & 2.908 & 2.908 & 2.908 & 2.908 & 2.908 & 2.908 & 2.908 & 2.908 \\
\hline Observation episodes & 40,714 & 40,714 & 40,714 & 40,714 & 40,714 & 40,714 & 40,714 & 40,714 \\
\hline & & & & & & & & \\
\hline Father dies & $1.096^{*}$ & & & & $1.232+$ & & & \\
\hline Father dies before the age of 5 & & 1.003 & & & & $1.845^{*}$ & & \\
\hline
\end{tabular}




\begin{tabular}{|c|c|c|c|c|c|c|c|c|}
\hline Father dies between the age of $5 \& 15$ & & & 0.964 & & & & 0.983 & \\
\hline Father dies after the age of 15 & & & & $1.145^{\star \star}$ & & & & $1.361+$ \\
\hline \multicolumn{9}{|l|}{ Social rank } \\
\hline (large-scale farmer is ref.) & 1 & 1 & 1 & 1 & 1 & 1 & 1 & 1 \\
\hline mid-scale farmers & 1.001 & 0.996 & 0.997 & 1.006 & 0.978 & 1.027 & 1.010 & 0.921 \\
\hline small-scale farmers & $1.220^{*}$ & $1.215^{*}$ & $1.214^{\star}$ & $1.217^{\star}$ & 1.193 & $1.248^{\star}$ & $1.185+$ & 1.169 \\
\hline Landless & $1.524^{* *}$ & $1.527^{\star \star}$ & $1.527^{\star \star}$ & $1.524^{\star *}$ & $1.706^{\star *}$ & $1.572^{\star \star}$ & $1.540^{\star \star}$ & $1.570^{\star \star}$ \\
\hline Unknown & $1.400^{* *}$ & $1.420^{* *}$ & $1.424^{* *}$ & $1.419^{* *}$ & $1.481^{* *}$ & $1.453^{\star *}$ & $1.422^{* *}$ & $1.411^{\star \star}$ \\
\hline \multicolumn{9}{|l|}{ Interaction social rank\#\#father's death } \\
\hline large-scale farmer (REF.) & & & & & 1 & 1 & 1 & 1 \\
\hline mid-scale farmers & & & & & 1.067 & $0.474+$ & 0.905 & 1.136 \\
\hline small-scale farmers & & & & & 1.064 & 0.467 & 1.206 & 0.901 \\
\hline Landless & & & & & $0.794+$ & $0.493^{*}$ & 0.930 & 1.016 \\
\hline Unknown & & & & & 0.895 & $0.553^{*}$ & 0.998 & 1.143 \\
\hline Mother dies & $1.200^{\star *}$ & $1.203^{\star \star}$ & $1.203^{\star \star}$ & $1.199^{\star \star}$ & $1.201^{\star \star}$ & $1.201^{\star \star}$ & $1.203^{\star \star}$ & $1.197^{\star \star}$ \\
\hline \multicolumn{9}{|l|}{$\begin{array}{l}\text { Number of older brothers } \\
\text { (time varying) }\end{array}$} \\
\hline 0 & 1 & 1 & 1 & 1 & 1 & 1 & 1 & 1 \\
\hline 1 & $0.907^{\star}$ & $0.908^{\star}$ & $0.907^{*}$ & $0.902^{\star}$ & $0.905^{\star}$ & $0.908^{\star}$ & $0.905^{*}$ & $0.903^{*}$ \\
\hline 2 & 0.957 & 0.957 & 0.957 & 0.957 & 0.952 & 0.962 & 0.956 & 0.953 \\
\hline $3+$ & $0.811^{\star}$ & $0.810^{*}$ & $0.809^{*}$ & $0.810^{*}$ & $0.806^{*}$ & $0.806^{*}$ & $0.808^{*}$ & $0.807^{\star}$ \\
\hline \multicolumn{9}{|l|}{$\begin{array}{l}\text { Number of younger brothers } \\
\text { (time varying) }\end{array}$} \\
\hline 0 & 1 & 1 & 1 & 1 & 1 & 1 & 1 & 1 \\
\hline 1 & 0.997 & 0.997 & 0.997 & 0.991 & 0.993 & 0.995 & 0.997 & 0.990 \\
\hline 2 & 0.948 & 0.941 & 0.940 & 0.936 & 0.947 & 0.942 & 0.938 & 0.936 \\
\hline $3+$ & 1.018 & 1.010 & 1.007 & 1.001 & 1.014 & 1.009 & 1.007 & 0.995 \\
\hline \multicolumn{9}{|l|}{$\begin{array}{l}\text { Number of older sisters } \\
\text { (time varying) }\end{array}$} \\
\hline 0 & 1 & 1 & 1 & 1 & 1 & 1 & 1 & 1 \\
\hline 1 & 0.950 & 0.951 & 0.950 & 0.949 & 0.951 & 0.950 & 0.952 & 0.947 \\
\hline 2 & $0.880+$ & $0.884+$ & $0.885+$ & $0.883+$ & $0.889+$ & $0.879+$ & $0.883+$ & $0.888+$ \\
\hline $3+$ & 0.911 & 0.911 & 0.912 & 0.917 & 0.918 & 0.920 & 0.910 & 0.926 \\
\hline \multicolumn{9}{|l|}{$\begin{array}{l}\text { Number of younger sisters } \\
\text { (time varying) }\end{array}$} \\
\hline 0 & 1 & 1 & 1 & 1 & 1 & 1 & 1 & 1 \\
\hline 1 & 0.936 & 0.931 & 0.930 & $0.923+$ & 0.934 & 0.931 & 0.929 & $0.916+$ \\
\hline 2 & 0.914 & $0.906+$ & $0.903+$ & $0.899+$ & 0.910 & 0.906 & $0.902+$ & $0.894+$ \\
\hline $3+$ & 0.971 & 0.956 & 0.953 & 0.954 & 0.973 & 0.957 & 0.953 & 0.951 \\
\hline \multicolumn{9}{|l|}{ Paternal age } \\
\hline$<20$ & 1.596 & 1.595 & 1.608 & 1.643 & 1.660 & 1.624 & 1.603 & 1.644 \\
\hline 20-30 (REF.) & 1 & 1 & 1 & 1 & 1 & 1 & 1 & 1 \\
\hline $30-40$ & $0.845^{\star \star}$ & $0.851^{\star \star}$ & $0.852^{\star \star}$ & $0.848^{\star \star}$ & $0.842^{\star \star}$ & $0.854^{\star \star}$ & $0.850^{\star \star}$ & $0.845^{\star \star}$ \\
\hline $40-50$ & $0.713^{\star *}$ & $0.723^{\star *}$ & $0.725^{\star *}$ & $0.716^{\star *}$ & $0.710^{\star *}$ & $0.723^{\star *}$ & $0.723^{\star \star}$ & $0.716^{\star *}$ \\
\hline $50-60$ & $0.584^{\star *}$ & $0.601^{\star \star}$ & $0.603^{\star \star}$ & $0.583^{\star \star}$ & $0.580^{\star \star}$ & $0.605^{\star \star}$ & $0.603^{\star \star}$ & $0.576^{\star \star}$ \\
\hline$>60$ & 0.836 & 0.880 & 0.893 & 0.849 & 0.790 & 0.878 & 0.838 & 0.861 \\
\hline Unknown & $0.827^{\star \star}$ & $0.837^{\star \star}$ & $0.839^{\star \star}$ & $0.831^{\star \star}$ & $0.824^{\star \star}$ & $0.837^{\star \star}$ & $0.839^{\star \star}$ & $0.829^{\star \star}$ \\
\hline \multicolumn{9}{|l|}{ Maternal age } \\
\hline$<20$ & 1.459 & 1.462 & 1.459 & 1.454 & 1.458 & 1.462 & 1.456 & 1.463 \\
\hline 20-30 (REF.) & 1 & 1 & 1 & 1 & 1 & 1 & 1 & 1 \\
\hline $30-35$ & 0.949 & 0.950 & 0.950 & 0.949 & 0.947 & 0.945 & 0.950 & 0.950 \\
\hline $35-45$ & 0.931 & 0.930 & 0.929 & 0.924 & 0.932 & 0.931 & 0.928 & 0.926 \\
\hline$>45$ & 1.329 & 1.345 & 1.334 & 1.254 & 1.262 & 1.347 & 1.348 & 1.218 \\
\hline Unknown & 0.975 & 0.978 & 0.978 & 0.972 & 0.982 & 0.977 & 0.977 & 0.979 \\
\hline Child's birth cohort & 1.000 & 0.999 & 0.999 & 1.000 & 1.000 & 0.999 & 0.999 & 1.000 \\
\hline
\end{tabular}




\begin{tabular}{|l|l|l|l|l|l|l|l|l|}
\hline (coded in decades) & & & & & & & & \\
\hline $\begin{array}{l}\text { Child's birth order } \\
(1=\text { firstborn) }\end{array}$ & $1.032^{*}$ & $1.034^{*}$ & $1.034^{*}$ & $1.033^{*}$ & $1.032^{*}$ & $1.034^{*}$ & $1.034^{*}$ & $1.032^{*}$ \\
\hline Standard errors in parentheses & & & & & & & & \\
\hline${ }^{* *} p<0.01,{ }^{*} p<0.05,+p<0.1$ & & & & & & & & \\
\hline
\end{tabular}

\subsection{Timing of father absence}

A comparison of the different Models B, C and D indicates that there was a timing effect of paternal loss on their offspring's age at first marriage. Model BI, BII, BIV (Table 3) indicate that paternal loss before the age of five was not associated with the girls' age at first marriage. Model CI and CII indicate that girls who experienced paternal loss between the age of five and 15 tended to marry earlier (hazard ratios $1.093+$ and $1.102+$, respectively) and Model DI and DII indicate that paternal loss after the age of 15 was significantly associated with a decreased age at first marriage for girls (hazard ratios $1.137 * *$ and $1.143 * *$, respectively). Interestingly, the fixed-effect Models BIV, CIV and DIV indicate that only paternal loss between the age of five and 15 was associated with an earlier marriage for girls (hazard ratio $1.308^{*}$ ). Similar results are indicated by models that estimate the boys' age at first marriage. Model BI, BII, BIV and CI, CII, CIV (both Table 4) indicate that neither the death of the father before the boys' age of five nor his death between the boys' age of five and fifteen was associated with the boys' age at first marriage. However, Model DI, DII, DIV indicate that boys who lost their fathers after the age of 15 married significantly earlier (hazard ratios $1.142 * *, 1.145^{* *}$ and $1.300^{*}$, respectively).

\subsection{Social group differentials}

As expected from the findings of the study by Willführ and Störmer (in press) we found that the mean age at first marriage varied for both boys and girls among the different social strata (Table 2). Girls from small-scale farmers, landless families and from families where the land-owning status is missing married significantly later when compared to girls from largescale farmer families (Table 4: Model AII-DII and AIII-DIII, respectively). The opposite is found for boys. Boys of small-scale farmers, landless families and from families where the land-owning status is missing were younger at their first marriage on average, when compared to boys of the wealth elite. In spite of these general differences between the social strata, we have found no significant interaction between paternal loss and social rank for girls (Table 3 , Model AIII-DIII). However, these models indicate indeed that paternal loss tended to 
decrease the girls' age at first marriage (Model AIII, hazard ratio $=1.195+)$; but in contrast to Model AI-DI, AII-DII and AIV-DIV that there was no timing effect. The results for boys (Table 4, Model AIII-DIII) indicate that their age at first marriage tended to be decreased, if the father died after the boys' $15^{\text {th }}$ birthday. Interestingly, Model BIII indicates that there was an interaction between early paternal loss and social rank for the boys' age at first marriage. Here, early paternal loss was also associated with a decreased age at first marriage for boys.

\subsection{Family differentials: sibship size and composition}

General effects of having siblings on age at first marriage:

The presence of older brothers is associated with an increased age at first marriage for both boys and girls (Table 3 and 4, Models IIA-D and Models IIIA-D). The strength of the effect increases with the number of older brothers and the fixed-effect models also indicate a correlation between the number of older brothers and delayed age at first marriage. The presence of younger brothers and sisters is linked to later marriage for girls (Table 3, Models IIA-D and Models IIIA-D), but not for boys (Table 4, Models IIA-D and Models IIIA-D). Having older sisters also appears to substantially delay the age at first marriage for girls, whereas no or only a weak impact is found for boys. Models IIA-D and Models IIIA-D (Table 4 ) indicate that boys having two older sisters tended to have a delayed marriage ( $>0.05$ and $\mathrm{p}<0.1$ ). Having one or three or more older sisters was not associated with a significant impact on the boys' age at marriage.

Interaction between the paternal absence effect with sibship size and sex composition:

To test whether the sibling scenario acted as a moderator on the effect of paternal loss on age at first marriage, we reran Models IIIA-D with interaction terms for the respective paternal loss dummy variables and time-varying information on having (1) older brothers, (2) younger brothers, (3) older sisters and (4) younger sisters (16 models for each sex, data not shown). Converging with the result of the regressions analyses shown in Table 3, these model series indicates that the girls' age at first marriage was lower when the father had died. In addition, paternal loss after the age of 15 appears to moderate the effect of having older brothers. The model controlling for the interaction between paternal loss after the age of 15 and the number of older brothers indicates that the paternal loss effect is fully moderated by two or more older brothers. In other words, girls who had no or just one older brother married no earlier when the father died after their 15 th birthday. We found further a significant interaction between paternal loss between the age of five and 15 and the number of younger 
brothers. The model indicates that girls married significantly earlier when their father died, but that this accelerating effect was weaker for girls who had one younger brother. Interestingly, we found no significant interaction between paternal loss and having older or younger sisters. The respective model series for boys converge with the results of the regression analyses given in Table 4. The boys' age at first marriage was decreased when the father had died and this effect was especially strong for paternal loss after the age of 15 . The models further indicate that this accelerating effect of paternal loss after the age of 15 was moderated by the number of older sisters. Thus, paternal loss did not significantly decrease the age at first marriage when there were no older sisters.

In sum we find that paternal loss had an accelerating effect on the age at first marriage for both girls and boys. In particular, this effect appears to be strong for both sexes when the father died after the age of 15 , but we also find that the effect of adult paternal loss was moderated by the number of older siblings. The effect on the girls' age at marriage was moderated by older brothers; the effect on the boys' age at marriage was moderated by older sisters. Furthermore, we find evidence that the girls' age at first marriage was also decreased when the father had died between the age of five and 15. This finding appears to be less moderated by the sibling scenario. As expected, we found general differences in the age at first marriage between the different social strata, but no or only weak evidence that social class moderated the effect of paternal loss.

\section{Discussion}

What is known from numerous other historical, traditional, and modern populations also applies to the Krummhörn population in the $18^{\text {th }}$ and $19^{\text {th }}$ centuries, namely that paternal absence does not remain without influence on the life history of a father's children. In particular, the transition to the generative life phase is accelerated. If the father dies, his sons and daughters marry earlier, on average, than if he survives.

The question of why this is so and whether this fact is accessible to an adaptive interpretation is interesting from a theoretical perspective. To check this, we have contrasted three evolutionarily informed theories and formulated expectations from their assumptions for the data set available (Table 1). The results assign differing probabilities to the three explanation attempts for their validity with regard to the Krummhörn. We did not find any support for the Life History Theory (LHT) explanation attempt, which essentially is based on 
the assumption that early paternal loss is interpreted as an indicator of a socially and ecologically insecure course of life for a child and therefore leads to an acceleration of the child's own reproduction. Merely Model BIII (Table 4), which examines the interaction between the paternal absence effect and affiliation with a social group, shows that the sons of large-scale farmers married earlier, if their father died before their fifth birthday. We assume, however, that not the mechanism of psychosocial acceleration is responsible for this, but the habit of the farmers to initially fill a vacancy left by the death of the father with a "Setzwirt", i.e., a temporary manager of the interests of the underage minors (Swart 1910). The institution of the "Setzwirt" was an interim solution, which was supposed to end as quickly as possible, therefore led to an above-average early onset of inheritance and marriage. If a psychosocial acceleration actually were taking place here we would have to find the same effect in the other social groups and with some probability also for the daughters of the prematurely deceased fathers. Instead, the other timing effects identified by us show that not paternal loss in childhood, but a later loss during and after adolescence carries the paternal absence effect to a significant degree. Therefore, the fundamental prerequisite for the LHT attempt at explanation is not visible in our models. However, this negative result does not in any way contradict the validity of the LHT approach. In an earlier study of the same population and two other historical samples from Finland and Canada, Störmer and Lummaa (2014), found that not the personal experience of mortality - measured against the number of personally experienced deaths of siblings - resulted in the accelerated marriage of the men. On the contrary, it is the mortality experience in families (independent of personal experience) which acts as an accelerator. Therefore, it does not appear to be ruled out that under the living conditions of the Krummhörn, with its increased mortality in comparison with modern populations, the death of the father is not enough to set the psychosocial acceleration into motion. It might possibly require an increased mortality in the families, to which the early decease of the father only contributes as an individual case but without any "special status". The missing link between mortality and life history adjustment could be some kind of "family mentality" (Störmer und Lummaa 2014). Completely in line with the thesis of humans as "cooperative breeders", this family climate which is possibly generated and processed through attachment styles may contribute to orchestrating personal life history adjustments within families.

We also have not found any cogent support for the parent-offspring conflict (POC) approach either, i.e., the assumption that the parent-offspring conflict subsides with the death of the father, which grants the children of the deceased more reproductive autonomy. This 
argument would have been supported by a finding that would have attributed a significant recognizable moderating role to the resource situation of the families. However, this is not visible in our models, which might be related to the fact that in view of the Krummhörn system of inheritance, only a few children would have been exposed to special expectations on the part of their father that would conflict with their own marriage interests. In view of the very low number of these cases, the effects could be diluted through the majority of the other cases. Moreover, it cannot be conclusively clarified whether the POC explanation also has certain validity in families without land ownership or not. Although the offspring of landless laborers did not have any material inheritance to expect, yet it is to be assumed that unmarried sons and daughters had a certain obligation towards their families as helpers, which was demanded by living fathers, if necessary. Both of these mechanisms with their differing causes could have led to a similar result of a delayed marriage. This could explain why the resource situation of the family did not have any visible influence on paternal absence in the models. Even if further and differentiating analyses are required, an initial conclusion can be drawn that the POC explanation attempt is unlikely to contribute to the interpretation of our models.

The Behavioral Ecology (BE) explanation attempt finds the strongest support through our analysis. The observation that paternal loss has an accelerating effect in the Krummhörn when it occurs at an age when the children would have been ready for marriage anyway or at least were soon going to be ready for marriage favors the assumption that paternal loss and accelerated marriage are closely and conditionally related and the expression of opportunistic decisions. However, the negative result with regard to the moderating role of the affiliation to a social class is somewhat unexpected. Even though the median age at first marriage varies between the social groups, we do not find any significant interaction with the paternal absence effect. A similar report comes from Sheppard et al. (2014) with regard to their Malaysia study. In their sample, parental wealth was a strong indicator of postponed marriage. Interestingly, in their models paternal absence was associated with a more rapid progression to marriage, even if wealth was included. In the Krummhörn, the loss of the father is obviously compensated for by early marriage and thus a change in generations was effected. It appears that this occurs independently of the family's social status. The culturally predominant concept of the family and family dynamics is possibly conceived of and cultivated across social strata, whereas stratum-specific demands are subordinated to the predominant image of the family. 
In particular, the moderating influence of the sibling scenario tends to support the viability of the behavioral ecology explanation. This is because after the death of the father, those children of marriageable age are confronted with older and young siblings with two different and conflicting interests, which have an impact on the marriage. On the one hand, younger siblings could require additional support after the death of the father, because the mother cannot fully compensate for the loss of the father, and on the other, older siblings could compel younger siblings to start their own families as quickly as possible. The decision to marry is not taken purely individualistically, but also against the background of family reproduction interests, completely in line with the predictions of the theory of cooperative breeding systems. Our methods are unable to further clarify according to which criteria precisely such decisions are made and how the adaptive functional logic of these decisions can be reconstructed. It is noticeable however, that older brothers hasten the accelerating impact of paternal loss on marriages both for sons and for daughters. On the other hand, older sisters retard the paternal absence effect for their younger brothers and at the same time, symmetrically younger brothers slow down the paternal absence effect for their older sisters. One is left with the impression that this sibling constellation generates a family stability which is also able to shield the family in part from the effects of paternal death. What it precisely is which attributes this moderating role in the family dynamics to older brothers on the one hand and the constellation of older sisters and younger brothers on the other hand, must remain subject to social history research. Information needed to be able to understand the adaptive background of the paternal loss effect in detail is still lacking at the moment. In particular, it is still completely unclear how ambivalent relationships among siblings in view of their simultaneous cooperation and competition (Nitsch et al. 2012, Pollet and Hoben 2011) are represented in the real life practice in the Krummhörn (and elsewhere).

From a behavioral ecology perspective, the transition to marriage is also the transition from the intrafamilial helper strategy to the breeder strategy, and therefore, there are many indications that also taking into account external cultural and socio-economic factors would contribute to a better understanding of the paternal absence effect, but especially an improved understanding of the adaptive mechanisms, such as the compromise between helping and breeding found in family networks. Ultimately, this includes the question of which regulating role fathers play in these networks and which channels paternal influences on the life history of their children utilize (Mattison et al. 2014, Shenk and Scelza 2012, Shenk et al. 2013, Winking et al. 2011). And what role do contextual factors, such as wealth, prestige, overall mortality, and many other factors play in the behavioral manifestation of the father role? In 
spite of these theoretical and empirical uncertainties, we believe that our models indicate on the whole that the behavioral theory offering provides the most suitable matrix for the paternal absence effect in the Krummhörn.

Of course, the three evolutionary attempts at explanation do not mutually rule each other out. On the contrary, it is justified to assume that they interact depending on the situation and the context. Therefore, it is not only conceivable but even very probable, that they entail varying effects in different samples with different weightings, respectively and that this is possibly different for the sexes. Actually there are indications that the LHT attempt finds an empirically broad and strong support in post-transitory, modern western societies, i.e., in societies with comparatively low mortality and a higher resource situation (e.g. Brumbach et al 2009, Chisholm et al. 2005, Nettle 2010). The accelerating effect of early father death is not masked in modern societies by other relevant factors, such as a generally increased mortality. In pre-modern societies on the other hand, the circumstances tend to head in the direction of the BE explanation attempts (Shenk et al. 2013, Sheppard et al. 2014). The analysis of the situation in the Krummhörn fits well into this picture. Nevertheless, the POC attempt at explanation has barely been the subject of any broad quantitative research to date. Although it is utilized occasionally in narrative and casuistic approaches (Flinn 1988, Gettler et al. 2015) and has also been modeled for analytic purposes (Moya and Sear 2014); nevertheless, assessments of its reach in real life contexts and the strength of its effect are hardly possible in a reliable way to date.

\section{References}

Allison P. D. 2009: Fixed Effects Regression Models. London (Sage)

Apostolou, Menealaos 2013: Sexual Selection Under Parental Choice: The Evolution of Human Mating Behaviour. Oxford (Psychology Press)

Belsky, Jay; Steinberg, Laurence; Draper, Patricia 1991: Childhood experience, interpersonal development, and reproductive strategy: An evolutionary theory of socialisation. Child Development 62: 647-670 
Brumbach, Barbara Hegenah; Figueredo, Aurelio José; Ellis, Bruce J. 2009: Effects of Harsh and Unpredictable Environments in Adolescence on Development of Life History Strategies - A Longitudinal Test of an Evolutionary Model. Human Nature 20: 25-51

Chisholm, James S. 1993: Death, Hope, and Sex - Life History and the Development of Reproductive Strategies. Current Anthropology 34: 1-24

Chisholm, James S.; Quinlian, Julie A.; Petersen, Rodney W.; Coall, David A. 2005: Early stress predicts age at menarche and first birth, adult attachment, and expected lifespan. Human Nature 16: 233-265

Cox, D. 1972: Regression models and life tables. Journal of the Royal Statistical Society Series B 34: 187-220

Draper, Patricia; Harpending, Henry 1982: Father Absence and Reproductive Strategy: An Evolutionary Perspective. Journal of Anthropological Research 38: 255-273

Ellis, Bruce J. 2004: Timing of Pubertal Maturation in Girls: An Integrated Life History Approach. Psychological Bulletin 130: 920-958

Flinn, Mark V. 1988: Parent-offspring interactions in a Caribbean village: Daughter guarding. pp. 189-200 in: Betzig, Laura; Borgerhoff Mulder, Monique \& Turke, Paul (eds.): Human Reproductive Behaviour - A Darwinian Perspective. Cambridge (Cambridge University Press)

Gettler, Lee T.; McDade, Thomas W.; Bragg, Jared M.; Feranil, Alan B.; Kuzawa, Christopher W. 2015: Developmental energetics, sibling death, and parental instability as predictors of maturational tempo and life history scheduling in males from Cebu, Philippines. American Journal of Physical Anthropology DOI 10.1002/ajpa.22783

Kramer, Karen L.; Greaves, Russell D.; Ellison, Peter T. 2009: Early reproductive maturity among Pumé foragers: Implications of a pooled energy model to fast life histories. American Journal of Human Biology 21: 430-437 
Mattison, Siobhán M.; Scelza, Brooke; Blumenfield, Tami 2014: Paternal investment and the positive effects of fathers among the matrilineal Mosuo of Southwest China. American Anthropologist 116: 591-610

Moya, C.; Sear, Rebecca 2014: Intergenerational conflicts may help explain parental absence effects on reproductive timing: a model of age at first birth in humans. Peerj 2: e512, doi.org/10.7717/peerj.512

Nettle, Daniel 2010: Dying young and living fast: Variation in life history across English neighborhoods. Behavioral Ecology 21: 387-395

Nitsch, Aida; Faurie, Charlotte; Lummaa, Virpi 2012: Are elder siblings helpers or competitors? Antagonistic fitness effects of sibling interactions in humans. Proceedings of the Royal Society B 280: 20122313

Ohling, Gerhard D. 1963: Kulturgeschichte des Krummhörn. pp. 17-288 in: Ohling, J. (Hrsg.): Die Acht und ihre sieben Siele. Pewsum (1. Entwässerungsverband Emden)

Pollet, Thomas V.; Hoben, Ashley D. 2011: An Evolutionary Perspective on Siblings: Rivals and Resources. pp. 128-148 in: Salmon, Catherine A.; Shackelford, Todd K. (eds.): The Oxford Handbook of Psychology. New York (Oxford University Press)

Reiches, Meredith W.; Ellison, Peter T.; Lipson, Susan F.; Sharrock, Katherine C.; Gardiner, Eliza; Duncan, Laura. G. 2009: Pooled Energy Budget and Human Life History. American Journal of Human Biology 21: 421-429

Rickard, Ian J.; Frankenhuis, Willem E.; Nettle, Daniel 2014: Why are childhood family factors associated with timing of maturation? A role for internal prediction. Perspectives on Psychological Science 9: 3-15

Scelza, Brooke A. 2010: Fathers' presence speeds the social and reproductive careers of sons. Current Anthropology 51: 295-303 
Shenk, Mary K.; Scelza, Brooke A. 2012: Paternal investment and status-related child outcomes: timing of father's death affects offspring success. Journal of Biosocial Science 44: 549-569

Shenk, Mary K.; Starkweather, Katherine; Kress, Howard C.; Alam, Nurul 2013: Does absence matter? A comparison of three types of father absence in rural Bangladesh. Human Nature 24: 76-110

Sheppard, Paula; Snopkowski, Kristin; Sear, Rebecca 2014: Father absence and reproductionrelated outcomes in Malysia, a transitional fertility population. Human Nature 25: 213 234

Störmer, Charlotte; Lummaa, Virpi 2014: Increased mortality exposure within the family rather than individual mortality experiences triggers faster life-history strategies in historic human populations. PLoS ONE 9(1): e83633

Swart, F. 1910: Zur friesischen Agrargeschichte. Leipzig (Duncker \& Humblodt)

Voland, Eckart 2000: Contributions of family reconstitution studies to evolutionary reproductive ecology. Evolutionary Anthropology 9: 134-146

Voland, Eckart 2014: The biological evolution of conscience - From parent-offspring conflict to morality. Anthropological Review 77: 251-271

Webster, Gregory D.; Graber, Julia A.; Gesselman, Amanda N.; Crosier, Benjamin S.; Orozco Schember, Tatiana 2014: A life history theory of father absence and menarche. A metaanalysis Evolutionary Psychology 12: 273-294

Willführ, Kai P.; Gagnon, Alain 2013: Are Stepparents Always Eevil? Parental Death, Remarriage, and Child Survival in Demographically Saturated Krummhörn (1720-1859) and Expanding Québec (1670-1750) Biodemography and Social Biology 59: 191-211

Willführ and Störmer, in press: Long-term trends and short-term fluctuations in the reproductive behavior of landless agricultural workers, small farmers, and the economic 
elite in the historical Krummhörn region (East Frisia, Germany, 1720-1870). Historical Life Course Studies

Winking, Jeffrey; Gurven, Michael; Kaplan, Hillard 2011: Father death and adult success among the Tsimane: Implications for marriage and divorce. Evolution and Human Behavior 32: 79-89 